\title{
Supply Portfolio Concentration in Outsourced Knowledge-Based Services
}

\author{
Mahka Moeen \\ Robert H. Smith School of Business, University of Maryland, College Park, Maryland 20742, \\ mmoeen@ rhsmith.umd.edu \\ Deepak Somaya, Joseph T. Mahoney \\ College of Business, University of Illinois Urbana-Champaign, Champaign, Illinois 61820 \\ \{dsomaya@illinois.edu, josephm@illinois.edu\}
}

\begin{abstract}
Tn the extant vertical integration literature, the question of how a firm's portfolio of outsourced work is managed across 1 suppliers has been relatively understudied. We seek to advance this area of research by examining factors that influence how concentrated the firm's outsourcing is among its set of suppliers. Using data on the outsourcing of patent legal services, we find empirical evidence that outsourced knowledge-based service work is concentrated in the hands of fewer suppliers when (1) it requires greater firm-specific knowledge, (2) there is a higher level of interrelatedness across outsourced projects, (3) the firm's reliance on outsourcing is high, (4) its outsourced projects are focused on a narrower (capability) domain, and (5) the technological dynamism of this domain is low. Our study suggests that examining portfolio-level phenomena in outsourcing is a useful complement to the predominant focus on transaction-level outcomes in prior research because it provides insights into how firms manage trade-offs across their entire set of outsourced projects.
\end{abstract}

Key words: outsourcing; knowledge-based services; governance inseparability

History: Published online in Articles in Advance April 3, 2012.

\section{Introduction}

The vertical integration literature has developed a number of important insights concerning when and why firms engage in strategic outsourcing. With outsourcing becoming more widespread and with suppliers playing a more critical role in a firm's success, research attention has shifted to strategic issues related to supplier management. In this spirit, the current paper examines how firms configure their suppliers at the portfolio level as a key dimension of supplier management requiring both theoretical explanation and empirical inquiry. A firm's outsourcing decisions can usefully be viewed as being made at two interrelated levels - the portfolio level and the transaction level. Although prior research has provided substantial insights into outsourcing and supplier management at the transaction level, research focused on portfolio-level questions-for example, how much to outsource, how many and which suppliers to include, and how to distribute work among suppliers-has been much more limited. Examining outsourcing at the portfolio level incorporates the understanding that a firm's set of transactions, which comprise its outsourcing portfolio, can exhibit significant interdependencies (Argyres and Liebeskind 1999, Kang et al. 2009, Mayer 2006) and may need to be examined collectively. Therefore, research at the portfolio level can provide a more complete understanding of outsourcing, including important new insights for both theory and practice.
In this paper, our research interest is in explaining and predicting how a firm-in response to shifting supplier management imperatives - may change the allocation of its portfolio of outsourced activities among its suppliers. For example, between 2001 and 2006, Cisco reduced its total number of suppliers from approximately 1,500 to 600 (Shao and Lee 2009). ${ }^{1}$ In 2001, the company spent $80 \%$ of its outsourcing dollars with 200 suppliers, but by 2006 its outsourcing had become much more focused, with just 95 suppliers accounting for $90 \%$ of Cisco's outsourcing dollars (Carbone 2006). Thus, the strategic shift in Cisco's outsourcing practices consisted of a reduction in the number of its suppliers and a simultaneous increase in the proportion of work outsourced to some select suppliers. The cumulative effect of these changes was an increase in the "concentration of outsourcing shares" among the firm's suppliers, which we label supply portfolio concentration.

Why then might firms want to increase their supply portfolio concentration and outsource to fewer suppliers? After all, distributing a firm's outsourcing among multiple suppliers can reduce its dependence on any single supplier, increase bargaining power, and enable price and capability benchmarking between suppliers. Consider Cisco's motivations for its strategic shift toward greater supply portfolio concentration-the company noted cost and time savings in managing fewer suppliers, the ability to work more closely with these suppliers, and 
the "leverage" it gained with select suppliers, who in turn became more responsive to the company's evolving (market-driven) needs (Carbone 2006). Furthermore, concentrating outsourcing in a smaller set of suppliers may enable each of these suppliers to make relationshipspecific investments and gain deeper knowledge of the firm's unique products, technologies, and procedures and thus provide more relevant and higher-quality services to the firm (Dyer and Singh 1998). It is important to note that such advantages operate at the portfolio level, where relational capital or firm-specific knowledge investments can be leveraged across multiple transactions between the firm and its supplier.

That said, higher levels of supply portfolio concentration may also mean that the firm becomes overreliant on a few suppliers, which poses strategic questions concerning how the firm will manage transaction hazards, monitor supplier performance, and take advantage of market forces that drive supplier efficiency and capability development. In Cisco's case, for example, the company recognized that it would be deepening its relationships and commitments with some chosen suppliers and that these suppliers needed to be chosen carefully based on the range and depth of their technological capabilities.

These trade-offs suggest that firms' supply portfolio choices should reflect the classic tensions between coordination and adaptation, which are highlighted in the organization economics literature (e.g., Bakos and Brynjolfsson 1993, Williamson 1985). When outsourcing knowledge-based work, closer exchange relationships with select suppliers can be advantageous for incentivizing firm-specific investments, greater responsiveness, safeguarding sensitive information, managing appropriability hazards, accounting for complementarities between projects, and generally coordinating better with each supplier (Dyer and Singh 1998, Novak and Stern 2009). However, focusing on fewer suppliers can also be limiting in important ways. In particular, a high supply portfolio concentration may constrain firms in accessing the full breadth of supplier capabilities available through the market (Argyres 1996, Leiblein and Miller 2003) and in quickly adapting to dynamic environments in which current supplier capabilities can become obsolete (Balakrishnan and Wernerfelt 1986). We build on these ideas concerning the opposing pressures firms face in managing their outsourcing to develop theorydriven hypotheses about when firms would choose higher (or lower) supply portfolio concentrations.

We test our developed hypotheses in the context of outsourced patent prosecution work-namely, the legal tasks of filing for patents and interacting with the patent office until the patent is granted. Data on patent work have a number of unique strengths and provide a useful context for testing theories about outsourcing in knowledge-based services. For example, compilation of information from patent documents and patent attorney databases enables us to access detailed data on the characteristics and outsourcing behavior of firms, as well as the knowledge attributes of outsourced work. Moreover, the patenting activities of firms are composed of large numbers of "work projects" - each centered on a single patent - of roughly similar type, which enables hypothesis testing that is not skewed by idiosyncratic or highly heterogeneous projects that sometimes characterize outsourcing in other knowledge-based services, such as information technology (IT). Furthermore, the availability of these data over time enables us to control for firm characteristics through the use of longitudinal econometric techniques and therefore to obtain more robust empirical results.

\section{Theoretical Background}

Building on the organizational economics literature, outsourcing research has examined several aspects of supplier management, such as supplier choice (Hoetker 2005), contract formulation (Mayer and Argyres 2004), formal and relational governance (Hoetker and Mellewigt 2009, Poppo and Zenger 2002), concurrent sourcing (Parmigiani 2007), and the impacts of information technologies (Clemons et al. 1993, Kim and Mahoney 2006, Lajili and Mahoney 2006). However, a critical assumption in much of this prior work-drawing on Williamson (1985) - is that the transaction is the unit of analysis. It has been recognized for some time now that transaction-level analysis can create constraints for developing a complete understanding of outsourcing. One limitation is that firm boundary decisions deemed appropriate when considering an individual transaction might be constrained by governance choices for other current transactions or prior contractual (or implicit) commitments of a firm, leading to governance inseparability (Argyres and Liebeskind 1999). Alternatively, considerations of a transaction's potential effect on future transactions in the form of knowledge and reputation spillovers (Kang et al. 2009, Mayer 2006) might justify governance choices that may have appeared to be strategic mistakes when viewed with the individual transaction as the unit of analysis. Recent research has noted that firm capabilities often arise from prior governance decisions, so spillovers between transactions can also occur from the path-dependent development and subsequent use of capabilities (Argyres and Zenger 2012, Mayer et al. 2012). Finally, coordination or complementarities among transactions might also lead to joint governance choice for a set of transactions (Novak and Stern 2009, Parmigiani and Mitchell 2009).

This paper builds on these theoretical advances and extends the organizational economics logic of governance inseparability to explain concentration in supply portfolios. Supply portfolio concentration (SPC) refers to the extent to which a firm apportions its outsourced 
activities or projects (of the same type) in a more or less concentrated manner among suppliers. High levels of SPC are indicated if most of the firm's outsourcing is to one or very few suppliers, whereas spreading the firm's outsourcing among a larger number of suppliers indicates low SPC. The analogy with an industry's market-share concentration suggests a natural (and robust) way to measure supply portfolio concentration by employing the Hirschman-Herfindahl Index (HHI), which is frequently used in industry analysis.

Inherently, a firm's strategies for supply portfolio management are related to and interact with transactionlevel choices about which projects it outsources and which suppliers it outsources individual projects to. However, this paper highlights the novel insights available through analysis at the portfolio level, which are often difficult to access through transaction-level analyses. Thus, it takes another step in freeing the outsourcing literature from constraints imposed by focusing on the transaction alone as the unit of analysis. For example, because investments in firm-specific knowledge and buyer-supplier relational capital can often be leveraged across multiple transactions between the same buyer and supplier, the need for these assets across the firm's outsourcing portfolio can influence supplier management in ways that are not captured by an analysis of any single transaction. Similarly, interrelationships and complementarities between transactions within the firm's portfolio may require coordinated choices across transactions (Novak and Stern 2009), which can influence decision making at the portfolio level. Portfolio-level attributes may also indicate a need for greater flexibility and adaptation to environmental conditions across the range of transactions undertaken by the firm, which may drive firms to involve more suppliers and to have less coordination with them. Therefore, a related research contribution of the current paper resides in examining the tension between coordination-related and adaptationrelated factors (Williamson 1985) that drive supply portfolio choices.

Portfolio-level choices about outsourcing are also inherently important; therefore, one of our contributions resides in highlighting these phenomena for research (i.e., in explaining a new type of dependent variable). In our hypotheses and empirical analyses, we develop a number of variables that predict the firm's level of SPC. Because the firm's outsourcing portfolio is ultimately composed of transactions, these portfolio-level drivers of SPC are naturally aggregations of transactional attributes. Some of the explanatory variables are simple aggregations (e.g., averages) of transactional attributes (firm-specific knowledge and technological dynamism), but other key variables are specifically derived from the composition of, or interrelationships between, transactions in the portfolio (interrelatedness, reliance on outsourcing, and domain diversity). Thus, an additional research contribution of our study is to develop a series of novel portfolio-level variables-consisting of simple or complex aggregations of transactional elements-that may explain portfolio-level outsourcing phenomena.

Changes in supply concentration at the portfolio level may sometimes go hand in hand with changes in the governance of outsourcing at the transaction level. Some attributes of the firm's outsourcing portfolio are associated with a more concentrated supply portfolio precisely because they require the development of longer-term relational arrangements with suppliers. It is important to note that these portfolio-level drivers of relational governance are in addition to any impetus for relational governance based on attributes of the focal transaction alone. Moreover, SPC is not always related to the governance of individual transactions in this way. Three portfolio-level variables we examine-namely, firm-specific knowledge, reliance on outsourcing, and technological dynamism-influence SPC through the (greater or lesser) need for closer exchange relationships with suppliers over time and can therefore affect governance arrangements at the transaction level. Thus, another contribution of the current paper is identifying portfolio-level characteristics relevant to future research on governance choices at the transaction level.

Additionally, this paper focuses on the outsourcing of knowledge-based services. The overall volume of outsourced knowledge work has grown rapidly in the economy, and this sector-consisting of services such as IT, accounting, consulting, legal, market research, design, and research and development (R\&D) - is now about as large as all of manufacturing. ${ }^{2}$ Some of our logic may extend to outsourcing in manufacturing as well, particularly in contexts where firms and suppliers develop and share valuable knowledge. However, manufacturing is not the focus of this paper. ${ }^{3}$

\section{Hypotheses Development}

In principle, firms may obtain several potential benefits from having a highly fragmented (or less concentrated) supplier set. These benefits generally stem from the action of market forces on supply relationships, resulting in access to diverse and "best in class" capabilities, greater supplier production cost efficiencies, and more bargaining power relative to suppliers. However, identifying and using additional suppliers require investments in searching for and vetting suppliers, negotiating contracts, managing relationships, and monitoring, all of which are costly and time-consuming actions. A greater volume of outsourcing enables a firm to spread these costs over multiple projects. Therefore, as a baseline, one may expect firms with higher levels of outsourcing to have a less concentrated (more fragmented) supply set. Below, we identify additional factors that may affect supply portfolio concentration beyond the baseline effect of the volume of outsourcing. 


\section{Firm-Specific Knowledge}

This paper posits that if the firm's outsourced knowledgebased work needs greater firm-specific knowledge on average across its entire portfolio, it will result in higher SPC. When knowledge-based projects are closely related to a unique technology, organizational unit, or strategic niche that is specific to a firm, acquisition of firm-specific knowledge by the supplier becomes imperative for effective task performance (Williamson 1985). Firm-specific knowledge investments are required to understand the firm's needs in the focal activity and to coordinate effectively with its managers and employees (Madsen et al. 2003, Nickerson and Zenger 2004), which represents a condition of high human asset specificity (Helfat 1994). Suppliers are thus required to make investments in knowledge that are only valuable for servicing the needs of a particular firm and cannot be redeployed to alternative uses and alternative users without sacrifice of the productive value (Ghemawat and del Sol 1998). When firm-specific knowledge is more valuable across the set of transactions outsourced by the firm, a supplier can potentially reuse such knowledge across multiple transactions outsourced by the firm. In turn, firms can induce suppliers to make firm-specific knowledge investments by ensuring them a larger share of outsourcing and limiting ex post competition between suppliers by reducing the number of suppliers (Bakos and Brynjolfsson 1993). For example, Dell was able to reach agreement with its suppliers to make Dell-specific investments by reducing the number of its suppliers from 204 to just 47 (Rangan and Bell 1999).

Market imperfections in the trading of knowledge (Teece 1980), information asymmetry (Arrow 1974), and time compression diseconomies (Dierickx and Cool 1989) make firm-specific knowledge a nontradable asset that must be developed and accumulated within the firm (Nelson and Winter 1982, Teece et al. 1997). Therefore, when suppliers need firm-specific knowledge to perform outsourced work, they typically only have access to this knowledge via prior implementation of related tasks and learning-by-doing (Hatch and Mowery 1998). For example, by working on the patents of a client, a patent law firm may develop a deeper understanding of the company's technologies, R\&D priorities and programs, market strategies, and ways of doing business, all of which are useful for future projects that build on this firmspecific knowledge. Although the activity could have been outsourced to any supplier at the outset, those suppliers that were able to develop firm-specific knowledge through prior outsourcing would gain an advantageous position over time relative to other suppliers. Put differently, the need for significant firm-specific knowledge in a firm's set of outsourced projects suggests that a fundamental transformation (Williamson 1985) from an ex ante competitive market to an ex post bilateral dependence has taken place. Because only a limited number of suppliers could develop such knowledge, and it can be leveraged across multiple firm-specific outsourcing projects, much of the firm's outsourced work may end up being handled by those limited suppliers that possess the firm-specific knowledge.

In addition, high firm specificity inherently implies that the focal knowledge activity or project has strategic value to the firm (Teece et al. 1997), and it may also signal the existence of related sets of proprietary knowledge assets that need to be disclosed to suppliers. Therefore, firms may face elevated appropriability hazards such that strategically important knowledge will leak out and get into the hands of competitors. A firm exhibiting sufficient foresight will require adequate economic safeguards to mitigate these appropriability hazards before entrusting suppliers with strategic knowledge; however, implementing and enforcing such economic safeguards (e.g., through relational governance) and developing relational capital (Dyer and Singh 1998) are costly and can only be justified with a small number of suppliers. As with firm-specific knowledge, relational capital developed with a supplier can also be leveraged across multiple transactions within the firm's outsourcing portfolio. Thus, such suppliers are placed in a superior position to undertake outsourced work that is more firm specific and are likely to obtain a disproportionate share of this work. Although the relevance of appropriability concerns can vary across outsourcing contextsfor example, because of variations in the availability and use of contractual provisions, institutional safeguards, and the strategic importance of the knowledge-based work-its marginal effect will nonetheless be in the same direction. This reasoning leads to the following hypothesis.

НуротнеSIS 1. The greater the need for firm-specific knowledge across the firm's portfolio of outsourced projects, the higher the concentration of the firm's supply portfolio, ceteris paribus.

\section{Interrelatedness}

Prior research suggests that contemporaneous interdependencies or complementarities between transactions are germane to outsourcing decisions (Milgrom and Roberts 1995). For example, when activities are interrelated, their vertical integration decisions are correlated (Novak and Stern 2009), and they are also more likely to be concurrently sourced (Parmigiani and Mitchell 2009). Similarly, the modularity literature highlights that modular products - which have limited interdependencies - are likely to lead to modularity in the associated organizational choices (Hoetker 2006, Sanchez and Mahoney 1996). In sum, the central insight of the extant literature is that when activities are interrelated, firms can benefit from making organizational choices that take account of potential complementarities and coordinate them effectively (Milgrom and Roberts 1995, Siggelkow 2002). 
Drawing on this prior research, we propose that interrelatedness among outsourced projects may influence the extent to which they are outsourced to a concentrated set of suppliers as opposed to a more distributed supplier set. If the firm's outsourced projects are interrelated, there may be complementarities that need to be coordinated across these projects. For example, in IT projects, it may be necessary to make sure that one IT component or system is able to work seamlessly with another. Similarly, in patent prosecution work, it may be necessary to modify or tweak the coverage of a given patent based on what is being described and claimed in others. Such interactions between outsourced projects will likely be easier to coordinate across a single (or fewer) supplier firm(s) than across multiple suppliers. Additionally, interrelated projects may also benefit from scope economies stemming from common knowledge or other resource inputs required for their execution. It has been long recognized that such scope economies are difficult to leverage across firm boundaries, particularly in the presence of market imperfections for trading the underlying knowledge resources between firms (Teece 1980). Thus, sets of interrelated projects may experience synergies such that joint execution of these projects by the same supplier yields positive spillovers that are more difficult to capture across multiple suppliers.

When viewed at the portfolio level, if there are greater interdependencies across outsourced projects in the firm's portfolio, it is economically valuable to actively coordinate these projects to capture complementarities or knowledge-based scope economies. In essence, we extend prior research that emphasizes the importance of contemporaneous spillovers between transactions (Argyres and Liebeskind 1999, Novak and Stern 2009) to complementarities across the entire set of transactions in the firm's portfolio. In sum, when the set of projects in the firm's outsourcing portfolio is highly interrelated, that creates an impetus for greater supply portfolio concentration because these interdependencies are more difficult to coordinate across larger sets of suppliers. Therefore, we hypothesize the following.

HYPOTHESIS 2. The greater the interrelatedness across the firm's portfolio of outsourced projects, the higher the concentration of the firm's supply portfolio, ceteris paribus.

\section{Reliance on Outsourcing}

The extent to which a firm relies on outsourcing in a particular type of knowledge-based work may have a bearing on its SPC. Outsourcing has several advantages for firms as market forces enhance efficiency and access to external capabilities. However, as a firm increases its reliance on outsourcing across its entire portfolio of activity, it also increases its dependency on suppliers as a whole, making it more vulnerable to expropriation by suppliers (Mayer and Salomon 2006). Therefore, the firm needs to establish governance mechanisms that protect it from potential transactional hazards stemming from higher exposure to outsourcing across its portfolio of projects, over and above what may be dictated by the hazards present in any individual transaction. Relational governance (Dyer and Singh 1998, Macneil 1980) has been suggested as a complement to formal explicit contracts to address such coordination challenges (Hoetker 2005, Poppo and Zenger 2002). Strategic commitment to repeated exchanges in long-term business relationships with a limited number of suppliers forms the basis for relational governance, which implies higher concentration in supplier choice.

Controlling for the volume of outsourcing, we consider the extent to which the firm uses-and thus relies on-outsourcing relative to the total volume of its activity. A greater reliance on outsourcing may itself arise from prior decisions to outsource, which can constrain current sourcing choices through path-dependent impacts on capabilities developed within the firm (Argyres and Zenger 2012, Mayer et al. 2012). Regardless of the origins, however, when firms rely heavily on suppliers for a given activity, relational governance improves firmsupplier relationships through at least three mechanisms. First, buyers might be shielded from economic holdup hazards, which may be higher when suppliers know that the firm cannot easily perform the same activities itself (Coff 1999). With relational governance, an expectation of benefits from future exchanges can outweigh benefits from self-interested moves at the expense of the buyer, so the supplier is less likely to act opportunistically (Klein and Leffler 1981). In addition to attenuating opportunistic behavior, accountability and responsiveness of the supplier to the buyer may be increased through relational governance. Furthermore, norms of information exchange and joint problem solving between a firm and its supplier(s) lead to the development of relational capital (Dyer and Singh 1998), which increases the likelihood of finding a prompt solution if the supplier faces a problem in delivering the outsourced work.

Second, vulnerabilities in exchange that are caused by deficient measurement and monitoring, which can be especially problematic when the output itself is a knowledge product, can frequently be overcome via cooperative norms (Ouchi 1979) that emerge in relational governance. The performance of outsourced knowledgebased services is often difficult to measure because of challenges in determining quality by observation or inspection (Barzel 1982) ${ }^{4}$ and in ascertaining supplier productivity in team production with the firm (Alchian and Demsetz 1972, Anderson and Schmittlein 1984). Because task programmability is also likely to be low in knowledge-based services (Jones 1984) that is, observed supplier inputs and sequences of supplier actions are poor measures of quality - both output 
monitoring and behavioral monitoring become ineffective (Mahoney 1992). Under these particular circumstances, cooperative norms help achieve a self-enforcing agreement or private ordering (Srinivasan and Brush 2006, Telser 1980) between the firms.

Third, a history of recurrent transactions with the same supplier under relational contracting decreases the supplier's ability to misrepresent its capabilities. Adverse selection in supplier choice (Akerlof 1970) may be a particularly vexing problem when reliance on outsourcing is high, because the firm does not have the capacity to internalize an activity quickly once it realizes that its supplier is deficient. However, after repeated transactions under relational contracting, the focal firm continues working only with those capable suppliers that have revealed their actual type.

Some benefits from relational governance are realized even if the firm's reliance on outsourcing is low. However, these benefits come at the cost of diminished market forces on suppliers and the substantial costs associated with building and maintaining relational governance with key suppliers. In turn, if there is a high reliance on outsourcing across the firm's portfolio of transactions, the benefits associated with relational governance may be high enough to justify these costs. Therefore, we hypothesize the following.

HYPOTHESIS 3. The greater the firm's reliance on outsourcing (as a percentage of the focal activity), the higher the concentration of the firm's supply portfolio, ceteris paribus.

\section{Supplier Capabilities and Domain Diversity}

Although outsourced knowledge-based work in a given area draws on the same broad technical or professional knowledge, projects can be in multiple domains within that area of work, such as technical or professional subfields or different application areas. For example, software development for inventory management and for human resources management comprises two different domains in IT services, each with its own unique needs and attributes. Adept suppliers of inventory management software may not possess strong capabilities for human resources software development, and vice versa. Thus, we propose that domain diversity in the firm's outsourced projects, which in turn requires diversity in its suppliers' capabilities, is inversely related to its supply portfolio concentration. By domain diversity, we mean the extent to which a firm's outsourced projects are distributed across many and relatively unrelated knowledge or capability domains.

The capabilities approach to organizational boundary choices finds that the relative capabilities of buyers and suppliers are key factors in firms' vertical integration decisions (Argyres 1996, Leiblein and Miller 2003). A firm's tendency to consider supplier capabilities relevant to its outsourced work has two implications for configuring its set of suppliers. First, firms will match outsourced projects in a given domain to suppliers based on whether they possess the required capabilities. Second, within this group of potential suppliers, a firm is more likely to outsource to the most capable supplier. Thus, when the firm needs to access a more diverse set of capabilities, these forces militate against the tendencies toward a more concentrated supply portfolio. Absent such imperatives to access diverse supplier capabilities, a firm is likely to outsource multiple projects in its portfolio to the same supplier(s) because of the potential benefits discussed in the preceding sections. In other words, although high SPC may be advantageous for relational governance, coordination across related transactions, and building firm-specific knowledge, it may also entail capability-related deficiencies in adapting to diverse task environments.

There may be practical limits to a supplier's capability development in multiple diverse domains. Suppliers develop capabilities in each domain through their prior experience in performing tasks related to that domain (Argyres and Zenger 2012, Leiblein and Miller 2003, Mayer et al. 2012); therefore, even if some capability exists in more than one domain, different emphases in the prior experiences of suppliers may lead to differential strengths across capability domains (Nelson 1991). Furthermore, because supplier output quality is often difficult to evaluate in knowledge-based services and specialization is assumed to be a signal of competence, supplier firms may remain relatively undiversified to signal their competence via specialization (von Nordenflycht 2010). Because the assignment of the outsourced projects to suppliers takes into account the supplier's capabilities in that domain, different suppliers are likely to be utilized, especially in unrelated areas. Accordingly, as a firm taps into outsourcing across more diverse domains, it may need to apportion its portfolio of outsourced work to a larger, more diverse set of suppliers, leading to lower concentration (greater fragmentation) in its supply portfolio. This logic leads to the following hypothesis.

НYРотHESIS 4. The greater the domain diversity across the firm's portfolio of outsourced projects, the lower the concentration of the firm's supply portfolio, ceteris paribus.

\section{Technological Dynamism}

The pace of technological change in the domains where the firm's outsourcing takes place is also likely to affect the firm's supply portfolio concentration. If underlying technologies are highly dynamic, implying rapid changes in the knowledge needed to execute outsourced projects, there is a higher probability that knowledgebased capabilities currently employed for the firm's outsourced tasks may become obsolete. In dynamic 
contexts, the nature of technological advancements may be unknown ex ante, which makes it difficult for firms and their suppliers to anticipate future capability requirements. Therefore, an important consideration for firms configuring their supply portfolios in dynamic technological environments is how to gain access to the required capabilities in case their suppliers' capabilities do not stay relevant. Because supplier capabilities may become obsolete, the future value of sunk bilateral investments in firm-specific knowledge and relational capital is likely to be lower (Balakrishnan and Wernerfelt 1986), thus diminishing the need to increase SPC to incentivize these investments. Further, if current suppliers do not adequately update their knowledge base, the firm may not be able to switch easily to new suppliers, because such a move is likely to entail significant costs (and time) in searching and evaluating suppliers and in developing working relationships with them (which may itself require a modicum of relational and firm-specific knowledge investments). Consequently, it may be advantageous to retain some degree of strategic flexibility in the supply portfolio and to limit the firm's reliance on particular suppliers. In other words, one potential impact of technological dynamism is to decrease the value of relation-specific investments and thus to engage in less concentrated outsourcing.

The logic provided above posits that the primary impact of technological dynamism is to decrease relation-specific investments, rather than to increase the difficulty of contracting (while holding specific investments constant), as the traditional transaction cost reasoning holds (Williamson 1985). The latter effect is suggested by potential concerns about so-called behavioral uncertainty (Williamson 1985), which can become problematic as a result of higher incompleteness in contracting and the greater need for bilateral adaptation in dynamic technology domains. Research in organizational economics has not settled which of these two mechanismsdriven by technological obsolescence or behavioral uncertainty, respectively-dominates when firms operate in fast-moving technological domains (Lajili et al. 2007, Mahoney 1992, Poppo and Zenger 1998). Indeed, after initially proposing the behavioral uncertainty rationale, Williamson (1999) suggested that when technology itself is in flux - such as at the developmental stage of a market - the calculus of its impact on governance may change. Moreover, empirical findings about the effects of technological uncertainty on outsourcing-related choices have also been equivocal (Afuah 2001, Balakrishnan and Wernerfelt 1986, Harrigan 1986, Hoetker 2005, Poppo and Zenger 1998, Walker and Weber 1984).

However, in outsourced knowledge-based services, concerns about the obsolescence of supplier capabilities are likely to trump issues related to behavioral uncertainty and incomplete contracting. One important factor is that outsourcing in this sector takes the form of distinct projects, and there is relatively little technological uncertainty when contracting over each of these projects. Thus, contractual incompleteness and associated challenges for adapting to technological change are less of a concern in knowledge-based services. Instead, changes in the technological landscape are more relevant to the risk that supplier capabilities may not keep up with the advancing technological frontier, thus undermining the value of spillovers between projects in the form of relational capital and firm-specific knowledge. Second, although changes in the underlying technology tend to impact the production of knowledge-based services directly through the need for new or different knowledge, rarely does it significantly impact the scope of work contracted for or the coordination of this work with other projects. With patent prosecution work, for example, suppliers are required simply to process the patent through a series of legal stages in exchange for payment that is either fixed or billed by the hour, and technological change does little to change this contractual equation. A useful contrast may be drawn with outsourcing for components, where technological change may necessitate both the delivery of a different work product and greater coordination with the buyer's overall product design (Hoetker 2005).

In sum, we conclude that the predominant concerns about obsolescence of supplier capabilities would make firms in knowledge-based services less likely to opt for relational contracting when technological dynamism is high (Balakrishnan and Wernerfelt 1986). Because contracting is typically at the project level, distributing outsourced projects among more suppliers enables the firm to draw on those suppliers whose capabilities remain relevant as the technology regime evolves, without the need to specify all contingencies of technological change and capability development in the initial contracts. Because firms may additionally wish to avoid the disruption and cost of finding new suppliers at short notice, we expect overall that technological dynamism will lead to lower SPC in knowledge-based services. This reasoning leads to the following hypothesis.

НуротнеSIS 5. The greater the technological dynamism across domain(s) of the firm's portfolio of outsourced projects, the lower the concentration of the firm's supply portfolio, ceteris paribus.

\section{Data and Methods}

\section{Sample}

We test our hypotheses by examining the set of suppliers used for outsourcing patent prosecution work in a sample of technology-based Fortune 500 firms over the period 1990-1995. Our focal sample of companies consists of 129 public U.S. firms in the 1989 Fortune 500 survey (published in 1990) from technology-based industries 
(i.e., chemicals; computer manufacturing; electronics; and pharmaceutical, scientific, and photographic equipment). Using the Directory of Corporate Affiliations, we identified the entire corporate family (subsidiaries and divisions) of each sample firm in each year. By matching corporate business units with their unique patent assignee codes at the U.S. Patent and Trademark Office (USPTO), we obtained all patents filed by our sample firms during the period 1990-1995. In essence, we replicate the NBER patent data set (Hall et al. 2001), albeit at a more detailed year-by-year level for a smaller sample of large firms. Based on this approach, we identified a total of 80,893 patents filed by these firms over six years (1990-1995), which we aggregated to the firm-year level of analysis. These patent-based data were augmented with yearly firm financial data from Standard \& Poor's Research Insight.

Our goal is to analyze the set of law firms (suppliers) used by our sample companies for outsourced patent prosecution work, which consists of drafting patent applications, filing them at the USPTO, and undertaking subsequent legal and administrative steps till the patent is granted. Patent prosecution work is typically done by patent attorneys, who are trained in both law and technology and must be admitted to the patent bar to practice before the patent office. Thus, patent work is typical of knowledge-based services, employing talented professionals located either within or outside the (client) firm. To be clear, we do not examine patent litigation work, which occurs later in the life of the patent and is largely outsourced to law firms.

Patent data have a number of strengths for studying outsourcing in knowledge-based services. First, each patent is a narrowly defined work project, and unlike other knowledge-based services, patent prosecution projects are by and large similar in the nature of work involved (which is to draft, file, and obtain a patent). Second, large companies typically file for many patents each year, making it feasible to control for firm effects and conduct longitudinal analysis of the data. Third, because patents contain rich data about the technological characteristics of the invention, it is possible to measure a number of focal and control variables related to patent legal projects. For all these reasons, data on patent (legal) outsourcing enable us to conduct well-controlled and robust tests of our theoretical propositions.

\section{Dependent Variable}

Our dependent variable measures the extent to which the outsourced patent prosecution work of a focal client company is concentrated within a few suppliers (law firms), as opposed to being distributed among a large number of suppliers. We measure this variable, supply portfolio concentration, using a Herfindahl-type index (HHI) of outsourced patents computed across different suppliers. We coded the supplier responsible for the patent prosecution work of each outsourced patent from the "Attorney or Agent" field on the patent, which lists up to three attorney and/or law firm names provided by the patentee when submitting the patent issuance fee to the USPTO. Where law firm names were absent, we cross-referenced the listed attorney names with the USPTO's yearly rosters of registered patent attorneys to identify the law firms that employed them. In the online appendix (available at http://dx.doi.org/10.1287/orsc.1110.0725), we explain these details and other checks and data updates we performed using the Patent Application Information Retrieval (PAIR) database of the USPTO. These analyses provide significant confidence in the accuracy of patent outsourcing data and our measures. After accounting for spelling differences and name changes, we identified a total of 534 unique law firms to which patents were outsourced in our sample.

We aggregated the number of patents outsourced by year from each firm to each supplier, and we employed these firm-supplier frequency counts to compute a nonbiased measure of SPC. HHI measures based on percentages (shares) computed from count data can be biased, and the bias increases when the total number of counts is small (Hall 2002). If $N_{i j t}$ denotes the number of patents outsourced by the $i$ th firm to supplier $j$ in year $t$, and $N_{i t}$ is the total number of patents outsourced by firm $i$ in year $t$, the unbiased measure of SPC is as follows (Hall 2002):

$$
\mathrm{SPC}=\frac{N_{i t} \sum_{j}\left[N_{i j t} / N_{i t}\right]^{2}-1}{N_{i t}-1},
$$

where $\sum_{j}\left[N_{i j t} / N_{i t}\right]^{2}$ is the (biased) HHI based on count shares.

This variable has a range between 0 and 1 , where a larger number implies higher supply portfolio concentration. Note that the unbiased estimate of $\mathrm{HHI}$ is undefined if $N_{i t}=1$. Moreover, the bias correction generates extreme values when $N_{i t}$ is small, which leads to high variance (noise) in our dependent variable. Thus, we restrict the data set to observations where at least three patents are outsourced (our results are robust to using four or five patents as the cutoff, as well as not applying the HHI bias correction).

\section{Independent Variables}

We measure our first independent variable, firm-specific knowledge, as the percentage of patent citations to the firm's own prior patents (self-citations) averaged over all the firm's outsourced patents in each year. A higher percentage of backward self-citations implies that the firm's outsourced patents build to a greater extent on its own inventions than on technologies invented more broadly in the economy. Because patent legal work requires 
detailed knowledge about the technological background of the patent, this variable directly measures the firm specificity of knowledge work that the firm outsourced. In using this measure, we implicitly build on prior work that explores the meaning of self-citations (Hall et al. 2001, Somaya 2003) and on research that has employed self-citations specifically to measure firmspecific knowledge (Wang and Chen 2010, Wang et al. 2009). We expect the coefficient of firm-specific knowledge to be positive.

The variable interrelatedness is measured by the extent to which a firm's outsourced patents are in connected (versus disconnected) subsets. Any two patents that share common backward citations are assumed to be connected to each other. If the firm's outsourced patents and the connections between them are represented by a graph, then each connected subset (that is also disconnected from others) is called a component of the graph. We use UCINET (Borgatti et al. 2002) to identify such components within each firm-year set of outsourced patents and measure interrelatedness by computing a (nonbiased) HHI of the distribution of patent shares into such subsets. For example, if all the firm's outsourced patents are connected to each other, they form one giant component, and their interrelatedness (HHI) is 1.0. However, with two equal-sized components, the interrelatedness evaluates to 0.25 . We also used two other measures for interrelatedness-density of the patent graph (defined as the ratio of connections in the graph to the maximum number of connections possible if all nodes were connected) and weighted density of the patent graph (where the weights are the fraction of joint citations shared by any two patents) - and found similar results. We expect the coefficient of interrelatedness to be positive.

We measure the firm's reliance on outsourcing by the percentage of patents that are outsourced each year by the firm-that is, the number of patents outsourced divided by the total number of patents applied for. We note below that the total volume of outsourcing is employed separately as a control variable. We expect the coefficient of reliance on outsourcing to be positive.

The independent variable domain diversity is measured using the technology classes of firms' outsourced patents. Knowledge about the technological area of the patent is an important prerequisite for performing patent prosecution work. Patent attorneys review prior art relevant to the patent, ensure that the patent describes the invention adequately, and draft patent claims to delimit the novel technological space that the firm seeks to "own," all of which require a detailed understanding of the technology domain of the invention. Patent documents report the technological domain of each patent by international patent classes (IPCs) or U.S. patent classes (USPCs). We use the IPC system because it is better structured than the USPC system (in particular, it is hierarchically nested) and organized with a single unifying logic (by technology area, rather than an ad hoc combination of technology and industry) (Lerner 1995). We measure domain diversity by computing a (nonbiased) HHI of the shares of a firm's outsourced patents across different four-digit IPCs in a given year and then subtracting it from 1. Like any taxonomy, the IPC draws sharp boundaries between technology areas even when they are in fact related. Therefore, an unadjusted HHI will not account for the relatedness among IPCs and will treat all IPCs as being perfectly unrelated (or orthogonal). To correct this potential bias, we need a valid measure of relatedness between IPCs and a method for adjusting the HHI. Our logic about domain diversity is ultimately about the availability of supplier capabilities across a diverse set of domains; therefore, we measure relatedness by the extent to which suppliers' volumes of patent prosecution work in any two IPCs is correlated (based on 163,524 patents handled by the 100 largest supplier law firms). Accordingly, we employ the following domain diversity measure: ${ }^{5}$

$$
\begin{aligned}
& \text { Domain diversity (adjusted } \mathrm{HHI} \text { ) } \\
& \quad=1-\sum_{k} \sum_{j}\left(p_{j}\right) \times\left(p_{k}\right) \times \operatorname{corr}\left(S_{j}, S_{k}\right),
\end{aligned}
$$

where $p_{j}$ and $p_{k}$ are the firm's shares of outsourced patents in IPC $j$ and $k$, respectively, and $S_{j}$ and $S_{k}$ are vectors of the shares of patents prosecuted by the 100 largest law firms in those IPCs. If all IPCs are unrelated, the correlations evaluate to 0 , and only the squared shares of the firm's patenting in IPCs factor into the computation, like a conventional HHI measure. Finally, we apply the HHI bias correction factor (Hall 2002). We expect the coefficient of domain diversity to be negative.

We measure technological dynamism using the weighted average of the growth rate of patenting across the technological domains (IPCs) associated with firm's outsourced projects. Specifically, we used the universe of patents issued by USPTO from 1986 to 1995 to compute the growth rate in each four-digit IPC based on a three-year moving average of the number of patents in that IPC. The growth rate of patents in an IPC measures the pace of innovation, which adds rapidly to the prior art and thus increases dynamism in the knowledge needed to carry out patent prosecution work within that technological domain. Because even a unit change in the number of patents leads to noisy fluctuations in the growth rate for IPCs with small numbers of patents, we only included the growth rates of IPCs with at least 10 issued patents during our 10-year observation window. The excluded IPCs are associated with only $1.75 \%$ of patents in our sample. We then computed the weighted average growth rate for each firm-year by weighting these growth rates with the share of firm's outsourced patents in each IPC in that year. We expect the coefficient of technological dynamism to be negative. 


\section{Controls}

To rule out potential alternative explanations for our empirical results, we control for a number of additional variables.

Outsourcing Volume. A baseline effect of decreased SPC is expected from higher outsourcing volume (measured by the logged number of patents outsourced). The lower the volume of outsourcing, the more constrained firms may find themselves in identifying and coordinating with additional suppliers.

Cites per Patent. We control for the average number of citations the firm's outsourced patents received in future years, which accounts for the potential value or importance of the firm's outsourced patents (Jaffe et al. 1998). This variable is adjusted for potential bias introduced by truncation of the series of forward citations (Hall et al. 2001).

$R \& D$ Expenditure. We control for the log of firms' $R \& D$ expenditures. $R \& D$ expenditures may represent the importance of innovation and, in turn, patenting for the firm.

Firm Size. We control for firm size with the log of firm's sales in each year.

Litigation Risk. To account for heterogeneities relating to potential patent litigation and address concerns about the impact of conflicts of interest, we controlled for the percentage of a firm's outsourced patents that cite any other previously litigated patent. Patent litigation data were collected from the LitAlert database of the USPTO (for District Court litigation) and combined with patent cases from the Section 337 forum of the U.S. International Trade Commission. Patents citing previously litigated patents are themselves around six times as likely to be litigated as the average patent (Mayer et al. 2012); accordingly, they can be viewed as a proxy for the litigation risk of a firm's patents.

Legal Market Size. The size of the firm's local market for patent legal services may influence its ability to farm out work to multiple suppliers. Legal market size is measured as the weighted average number of patent attorneys (in hundreds) across metropolitan statistical areas (MSAs) in a given year, where the weights are the fraction of the firm's internal attorneys (who are critical boundary spanners that interact with external attorneys) in each MSA. If the focal firm had no internal attorneys in a given year, we used its headquarters location (with weight $=1$ ).

Technology Areas. The firms in our sample straddle a variety of industries, and we seek to control for the primary technology areas, and changes in technology areas, in which they are active. Thus, we employ a set of widely used technology groupings based on USPCs
(Jaffe 1998) and control for the fraction of the firm's patents that fall into each of these technology areasnamely, drugs and medical; chemical; electronics, computers, optical, and nuclear; and mechanical ("other" is the reference category).

Year Dummies. We include a dummy variable for each (filing) year (1995 is the reference year).

\section{Econometric Models}

In our econometric models, we seek to explain supply portfolio concentration in the firm's set of outsourced projects, conditional on the extent of outsourcing by the firm. The data consist of firm-year longitudinal panels, and we use panel data econometric techniques. Because 9\% of observations consist of outsourcing to a single supplier, our dependent variable, supply portfolio concentration, is truncated at 1 for these observations. Therefore, we apply econometric models appropriate for a truncated dependent variable, i.e., Tobit models (Tobin 1958). Conditional fixed-effects Tobit estimates are inconsistent (Greene 2004), so our primary econometric model is the random-effects Tobit (Matyas and Sevestre 2008). To evaluate robustness, we estimated random- and fixed-effects ordinary least squares (OLS) models, and these estimates are discussed following our main results. We also conducted a Hausman's (1978) specification test and found that we could not reject the null hypothesis that the random-effects estimates are consistent, which supports the use of random-effects models for our main results.

\section{Results}

We examine the drivers of SPC in outsourced legal patent work, and larger values of our dependent variable imply higher SPC. Tables 1 and 2 present the descriptive statistics of our data and the correlation table, respectively. Table 3 reports results from our main randomeffects Tobit models, wherein Model 1 only includes control variables. In Models 2, 3 and 4, the coefficients of firm-specific knowledge, interrelatedness, and reliance on outsourcing - each introduced separatelyare positive as hypothesized and significant at the $1 \%$ level. In Models 5 and 6, the coefficients of domain diversity and technological dynamism are negative as hypothesized and significant at the $1 \%$ and 5\% levels, respectively. Model 7 includes all variables, and the estimated coefficients retain the same sign and significance levels as the earlier models except for firmspecific knowledge, which is significant at the 5\% level in model 7. Overall, Table 3 provides strong corroboration for all five of our hypotheses.

To evaluate the robustness of our empirical results, we conducted a number of supplementary analyses with alternative model specifications. As noted earlier, our 
Table 1 Descriptive Statistics of Key Variables

\begin{tabular}{|c|c|c|c|c|c|}
\hline Variable & Measure & Mean & S.D. & $\begin{array}{l}\text { Between } \\
\text { S.D. }\end{array}$ & $\begin{array}{l}\text { Within } \\
\text { S.D. }\end{array}$ \\
\hline Supply portfolio concentration & $\begin{array}{l}\text { Nonbiased HHI based on shares of outsourced patents } \\
\text { among suppliers }\end{array}$ & 0.409 & 0.285 & 0.265 & 0.159 \\
\hline Firm-specific knowledge & $\begin{array}{l}\text { Percentage of backward cites in the firm's outsourced } \\
\text { patents that are to its own prior patents }\end{array}$ & 0.097 & 0.079 & 0.074 & 0.049 \\
\hline Interrelatedness & $\begin{array}{l}\text { Nonbiased HHI based on shares of outsourced patents } \\
\text { in connected subsets (components) of backward } \\
\text { citations graph }\end{array}$ & 0.066 & 0.087 & 0.071 & 0.066 \\
\hline Reliance on outsourcing & Percentage of outsourcing & 0.555 & 0.377 & 0.375 & 0.094 \\
\hline Domain diversity & $\begin{array}{l}\text { Nonbiased HHI based on shares of outsourced patents } \\
\text { in technology domains (IPCs) adjusted for the } \\
\text { relatedness between IPCs based on supplier } \\
\text { capabilities, subtracted from } 1\end{array}$ & 0.715 & 0.198 & 0.181 & 0.101 \\
\hline Technological dynamism & $\begin{array}{l}\text { Weighted average of growth rate of patenting in } \\
\text { technology domains (IPCs) weighted by the share of } \\
\text { firm's outsourced patents in each IPC }\end{array}$ & 0.058 & 0.054 & 0.039 & 0.039 \\
\hline Outsourcing volume & (Log) No. outsourced patents & 3.058 & 1.076 & 0.972 & 0.464 \\
\hline Cites per patent & Average no. of forward cites to an outsourced patent & 10.828 & 7.299 & 5.855 & 4.185 \\
\hline$R \& D$ expenditure & (Log) Firm's R\&D expenditure & 5.090 & 1.451 & 1.543 & 0.222 \\
\hline Firm size & (Log) Firm's sales & 8.224 & 1.063 & 1.033 & 0.181 \\
\hline Litigation risk & $\begin{array}{l}\text { Percentage of a firm's outsourced patents that cite any } \\
\text { other previously litigated patent }\end{array}$ & 0.149 & 0.093 & 0.102 & 0.000 \\
\hline Legal market size & $\begin{array}{l}\text { Number of patent attorneys (in hundreds) in an MSA } \\
\text { weighted by the fraction of the firm's internal attorneys } \\
\text { in the same MSA }\end{array}$ & 8.111 & 7.159 & 7.451 & 1.266 \\
\hline Drugs and medical & Fraction of firm patents in technology area & 0.139 & 0.272 & 0.252 & 0.094 \\
\hline Chemical & Fraction of firm patents in technology area & 0.199 & 0.259 & 0.252 & 0.094 \\
\hline $\begin{array}{l}\text { Electronics, computers, } \\
\text { optical, and nuclear }\end{array}$ & Fraction of firm patents in technology area & 0.473 & 0.396 & 0.387 & 0.094 \\
\hline Mechanical & Fraction of firm patents in technology area & 0.16 & 0.195 & 0.198 & 0.090 \\
\hline
\end{tabular}

results were unaffected when we dropped the bias correction for HHI-based variables, used alternative cutoffs to exclude observations with missing data about supplier identity, employed alternative measures for interrelatedness, and dropped the relatedness adjustment for domain diversity. In supplementary analyses, we also compared our random-effects Tobit findings with random-effects and fixed-effects OLS models. Random-effects OLS estimates approximate our Tobit results quite well, albeit with somewhat smaller but statistically significant coefficient sizes. In fixed-effects models, the significance levels of some (potentially inconsistent) coefficients are lower, but the same overall pattern of results is maintained. Thus, these additional models also broadly corroborate our reported findings.

Having discussed the statistical significance and robustness of our findings, we turn our attention to the magnitudes (or economic impacts) of the estimated coefficients (Ziliak and McCloskey 2004). We examine these impacts relative to one standard deviation of each independent variable. A one-S.D. increase in firm-specific knowledge (0.079 units) is associated with an increase in supply portfolio concentration of 0.03 units. Similarly, a one-S.D. increase in interrelatedness (0.087 units) and reliance on outsourcing (0.377 units) corresponds to increases in SPC of 0.04 units and
0.102 units, respectively. Finally, a one-S.D. increase in domain diversity (0.198 units) and technological dynamism (0.054 units) would lead to 0.063-unit and 0.036-unit decreases in SPC. Cumulatively, the combined impact of a one-standard deviation change in these five variables is approximately equal to the firm going from 16 suppliers to just 3 , each receiving an equal share of the firm's outsourcing. Based on these analyses, we conclude that the impacts on supply portfolio concentration resulting from changes in our explanatory variables are quite large and economically impactful.

\section{Limitations and Additional Analyses}

Although our empirical findings have important implications for theory and practice, this study is not without limitations. First, our empirical evidence is limited to a sample of outsourced patent prosecution services in a particular time period and may not hold in other settings and time periods. For example, we focus on outsourcing by large Fortune 500 firms; however, small and large firms may differ in their organizational structures, internal resource constraints, and governance capabilities (Mayer and Salomon 2006), which can translate into different strategies for managing suppliers. Furthermore, the strategic flexibility to outsource work to multiple suppliers might not be available outside of knowledgebased services; for example, manufacturing settings may 


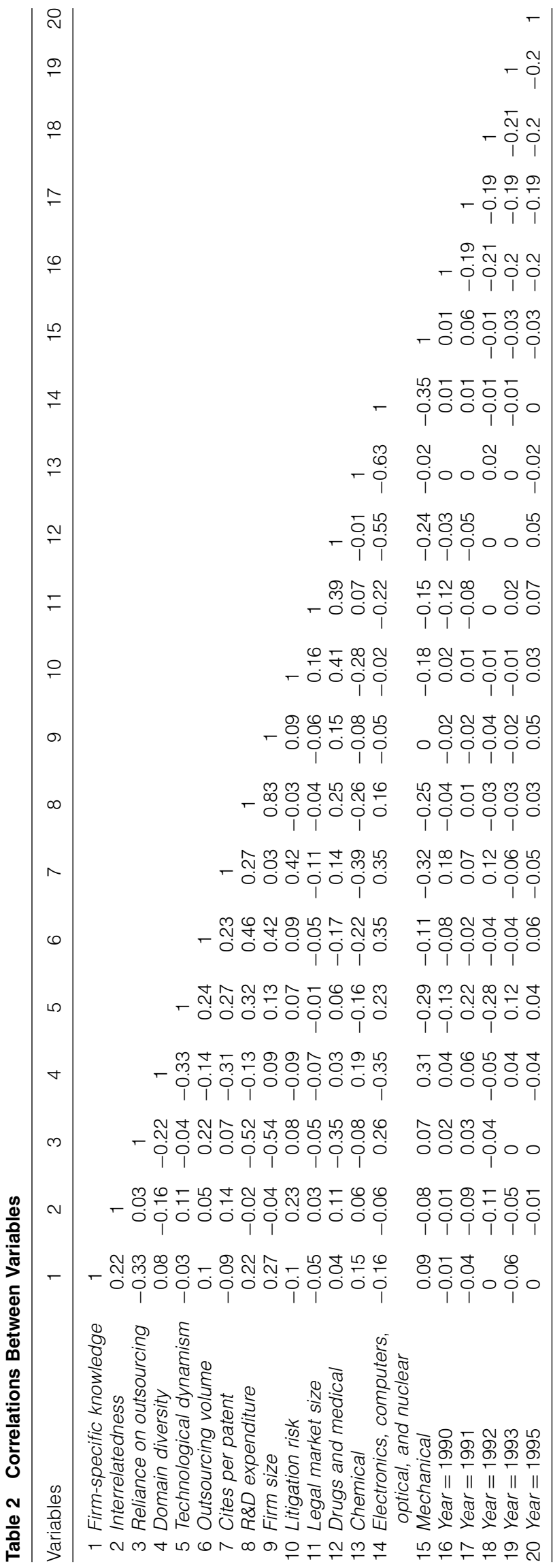

be characterized by increasing returns to scale or suppliers with strong market power, which may become the dominant considerations in these settings. Moreover, although patent legal work is an important support activity and a valuable complementary capability for technology firms, it is generally not considered a primary source of competitive advantage. Empirical findings from this context may therefore not hold in other more "missioncritical" knowledge-based services. Additionally, patent prosecution work is typically conducted by single attorneys or small teams of attorneys, and our findings may not generalize to larger, more complex, knowledge-based services. Future research can build on this study by explaining the drivers of supply portfolio concentration in alternative settings.

Another characteristic of patent legal work is that appropriability hazards may be relatively low because the suppliers (law firms) are bound by attorney-client privilege and are also unlikely to become competitors. In other contexts, the leakage of proprietary knowledge to suppliers who constitute more significant appropriability risks may have a bigger impact on how the firm apportions its outsourcing among suppliers. In developing our hypotheses, we listed multiple mechanisms through which certain factors-such as firm-specific knowledge-can affect supply portfolio concentration. Although these multiple mechanisms all impact SPC in the same direction, we cannot empirically discriminate between them. As the example of appropriability hazards illustrates, these mechanisms may play different roles and matter to different extents across industry settings. Therefore, future research can shed further light on the differences between these mechanisms and on their relevance to different knowledge-based services.

Law firms are constrained by ethical rules and guidelines in accepting business from multiple clients when there are clear conflicts of interest (Oddi 2004). Other knowledge-based services may also be similarly constrained, but their conflicts of interest are arguably less regulated than in legal services. However, conflicts of interest in patent prosecution work appear to be quite narrow in scope and may be even less important for an aggregate phenomenon such as SPC (especially with a longitudinal empirical design). ${ }^{6}$ It is difficult to identify conflicts of interest directly in our data, but these conflicts are expected to be substantially higher in the context of patent litigation (Oddi 2004). Thus, our control variable, litigation risk, is a proxy for potential conflicts of interest. Additionally, client firms may use conflicts of interest strategically by working with multiple legal suppliers to constrain the supplier options available to competitors in litigation. In particular, this strategy may be attractive in technologically dynamic areas and thus provide an alternative explanation for Hypothesis 5. Interestingly, we find that neither litigation risk nor its interaction with technological dynamism has 
Table 3 Determinants of Supply Portfolio Concentration in Outsourcing Patent Legal Work (Random-Effects Tobit Models)

\begin{tabular}{|c|c|c|c|c|c|c|c|}
\hline & Model 1 & Model 2 & Model 3 & Model 4 & Model 5 & Model 6 & Model 7 \\
\hline Firm-specific knowledge & & $\begin{array}{l}0.519^{* * *} \\
(0.192)\end{array}$ & & & & & $\begin{array}{c}0.381^{* *} \\
(0.189)\end{array}$ \\
\hline Interrelatedness & & & $\begin{array}{l}0.572^{* * *} \\
(0.164)\end{array}$ & & & & $\begin{array}{l}0.471^{* * *} \\
(0.167)\end{array}$ \\
\hline Reliance on outsourcing & & & & $\begin{array}{l}0.285^{* * *} \\
(0.090)\end{array}$ & & & $\begin{array}{l}0.272^{* * *} \\
(0.085)\end{array}$ \\
\hline Domain diversity & & & & & $\begin{array}{c}-0.364^{* * *} \\
(0.094)\end{array}$ & & $\begin{array}{c}-0.318^{* * *} \\
(0.091)\end{array}$ \\
\hline Technological dynamism & & & & & & $\begin{array}{c}-0.563^{* *} \\
(0.286)\end{array}$ & $\begin{array}{c}-0.673^{* *} \\
(0.278)\end{array}$ \\
\hline Outsourcing volume & $\begin{array}{r}-0.035^{*} \\
(0.021)\end{array}$ & $\begin{array}{c}-0.032 \\
(0.021)\end{array}$ & $\begin{array}{c}-0.043^{* *} \\
(0.021)\end{array}$ & $\begin{array}{c}-0.082^{* * *} \\
(0.026)\end{array}$ & $\begin{array}{c}-0.036 \\
(0.020)\end{array}$ & $\begin{array}{c}-0.032 \\
(0.021)\end{array}$ & $\begin{array}{c}-0.082^{* * *} \\
(0.024)\end{array}$ \\
\hline Cites per patent & $\begin{array}{c}0.004 \\
(0.003)\end{array}$ & $\begin{array}{c}0.004 \\
(0.003)\end{array}$ & $\begin{array}{c}0.002 \\
(0.003)\end{array}$ & $\begin{array}{c}0.003 \\
(0.003)\end{array}$ & $\begin{array}{c}0.002 \\
(0.003)\end{array}$ & $\begin{array}{c}0.004 \\
(0.003)\end{array}$ & $\begin{array}{c}0.002 \\
(0.003)\end{array}$ \\
\hline$R \& D$ expenditure & $\begin{array}{c}-0.004 \\
(0.034)\end{array}$ & $\begin{array}{c}-0.003 \\
(0.033)\end{array}$ & $\begin{array}{c}0.005 \\
(0.033)\end{array}$ & $\begin{array}{c}0.025 \\
(0.034)\end{array}$ & $\begin{array}{c}-0.014 \\
(0.032)\end{array}$ & $\begin{array}{c}-0.002 \\
(0.034)\end{array}$ & $\begin{array}{c}0.027 \\
(0.032)\end{array}$ \\
\hline Firm size & $\begin{array}{c}-0.065 \\
(0.045)\end{array}$ & $\begin{array}{r}-0.075^{*} \\
(0.045)\end{array}$ & $\begin{array}{c}-0.065 \\
(0.044)\end{array}$ & $\begin{array}{c}-0.028 \\
(0.045)\end{array}$ & $\begin{array}{c}-0.043 \\
(0.043)\end{array}$ & $\begin{array}{c}-0.065 \\
(0.045)\end{array}$ & $\begin{array}{c}-0.018 \\
(0.042)\end{array}$ \\
\hline Litigation risk & $\begin{array}{c}0.089 \\
(0.312)\end{array}$ & $\begin{array}{c}0.120 \\
(0.309)\end{array}$ & $\begin{array}{c}0.005 \\
(0.304)\end{array}$ & $\begin{array}{c}-0.007 \\
(0.307)\end{array}$ & $\begin{array}{c}0.119 \\
(0.288)\end{array}$ & $\begin{array}{c}0.083 \\
(0.316)\end{array}$ & $\begin{array}{c}-0.032 \\
(0.282)\end{array}$ \\
\hline Legal market size & $\begin{array}{c}-0.002 \\
(0.004)\end{array}$ & $\begin{array}{c}-0.001 \\
(0.004)\end{array}$ & $\begin{array}{c}-0.001 \\
(0.004)\end{array}$ & $\begin{array}{c}-0.001 \\
(0.004)\end{array}$ & $\begin{array}{c}-0.002 \\
(0.004)\end{array}$ & $\begin{array}{c}-0.002 \\
(0.004)\end{array}$ & $\begin{array}{c}0.000 \\
(0.004)\end{array}$ \\
\hline Drugs and medical & $\begin{array}{c}-0.361 \\
(0.241)\end{array}$ & $\begin{array}{r}-0.438^{*} \\
(0.240)\end{array}$ & $\begin{array}{r}-0.411^{*} \\
(0.237)\end{array}$ & $\begin{array}{c}-0.327 \\
(0.238)\end{array}$ & $\begin{array}{c}-0.513^{* *} \\
(0.238)\end{array}$ & $\begin{array}{c}-0.336 \\
(0.240)\end{array}$ & $\begin{array}{c}-0.527^{* *} \\
(0.231)\end{array}$ \\
\hline Chemical & $\begin{array}{c}0.004 \\
(0.226)\end{array}$ & $\begin{array}{c}-0.050 \\
(0.225)\end{array}$ & $\begin{array}{c}-0.050 \\
(0.223)\end{array}$ & $\begin{array}{c}0.018 \\
(0.223)\end{array}$ & $\begin{array}{c}-0.099 \\
(0.223)\end{array}$ & $\begin{array}{c}0.023 \\
(0.225)\end{array}$ & $\begin{array}{c}-0.129 \\
(0.215)\end{array}$ \\
\hline $\begin{array}{c}\text { Electronics, computers, } \\
\text { optical, and nuclear }\end{array}$ & $\begin{array}{r}-0.052 \\
(0.226)\end{array}$ & $\begin{array}{r}-0.099 \\
(0.224)\end{array}$ & $\begin{array}{c}-0.078 \\
(0.222)\end{array}$ & $\begin{array}{c}-0.065 \\
(0.223)\end{array}$ & $\begin{array}{c}-0.207 \\
(0.224)\end{array}$ & $\begin{array}{c}-0.038 \\
(0.225)\end{array}$ & $\begin{array}{r}-0.235 \\
(0.216)\end{array}$ \\
\hline Mechanical & $\begin{array}{r}-0.059 \\
(0.239)\end{array}$ & $\begin{array}{r}-0.140 \\
(0.238)\end{array}$ & $\begin{array}{r}-0.105 \\
(0.235)\end{array}$ & $\begin{array}{c}-0.062 \\
(0.235)\end{array}$ & $\begin{array}{r}-0.183 \\
(0.236)\end{array}$ & $\begin{array}{r}-0.063 \\
(0.237)\end{array}$ & $\begin{array}{c}-0.272 \\
(0.228)\end{array}$ \\
\hline Year $=1990$ & $\begin{array}{r}-0.048 \\
(0.043)\end{array}$ & $\begin{array}{r}-0.036 \\
(0.043)\end{array}$ & $\begin{array}{r}-0.009 \\
(0.044)\end{array}$ & $\begin{array}{r}-0.047 \\
(0.043)\end{array}$ & $\begin{array}{r}-0.030 \\
(0.043)\end{array}$ & $\begin{array}{r}-0.061 \\
(0.043)\end{array}$ & $\begin{array}{r}-0.005 \\
(0.043)\end{array}$ \\
\hline Year $=1991$ & $\begin{array}{r}-0.043 \\
(0.042)\end{array}$ & $\begin{array}{r}-0.033 \\
(0.041)\end{array}$ & $\begin{array}{r}-0.002 \\
(0.043)\end{array}$ & $\begin{array}{c}-0.037 \\
(0.041)\end{array}$ & $\begin{array}{r}-0.023 \\
(0.042)\end{array}$ & $\begin{array}{r}-0.028 \\
(0.042)\end{array}$ & $\begin{array}{c}0.038 \\
(0.042)\end{array}$ \\
\hline Year = 1992 & $\begin{array}{r}-0.072^{*} \\
(0.039)\end{array}$ & $\begin{array}{r}-0.066^{*} \\
(0.039)\end{array}$ & $\begin{array}{l}-0.028 \\
(0.041)\end{array}$ & $\begin{array}{r}-0.061 \\
(0.039)\end{array}$ & $\begin{array}{r}-0.069^{*} \\
(0.039)\end{array}$ & $\begin{array}{c}-0.092^{* *} \\
(0.040)\end{array}$ & $\begin{array}{c}-0.042 \\
(0.041)\end{array}$ \\
\hline Year $=1993$ & $\begin{array}{c}-0.080^{* *} \\
(0.037)\end{array}$ & $\begin{array}{r}-0.070^{*} \\
(0.037)\end{array}$ & $\begin{array}{r}-0.050 \\
(0.038)\end{array}$ & $\begin{array}{c}-0.079^{* *} \\
(0.037)\end{array}$ & $\begin{array}{r}-0.067^{*} \\
(0.038)\end{array}$ & $\begin{array}{c}-0.071 \\
(0.037)\end{array}$ & $\begin{array}{c}-0.023 \\
(0.037)\end{array}$ \\
\hline Year $=1994$ & $\begin{array}{r}-0.063 \\
(0.037)\end{array}$ & $\begin{array}{r}-0.054 \\
(0.036)\end{array}$ & $\begin{array}{c}-0.032 \\
(0.037)\end{array}$ & $\begin{array}{r}-0.065 \\
(0.036)\end{array}$ & $\begin{array}{r}-0.058 \\
(0.037)\end{array}$ & $\begin{array}{c}-0.061 \\
(0.036)\end{array}$ & $\begin{array}{r}-0.026 \\
(0.036)\end{array}$ \\
\hline Constant & $\begin{array}{l}1.202^{* * *} \\
(0.365)\end{array}$ & $\begin{array}{l}1.251^{* * *} \\
(0.361)\end{array}$ & $\begin{array}{l}1.169^{* * *} \\
(0.357)\end{array}$ & $\begin{array}{c}0.739 \\
(0.385)\end{array}$ & $\begin{array}{l}1.463^{* * *} \\
(0.355)\end{array}$ & $\begin{array}{c}1.199 * * \\
(0.365)\end{array}$ & $\begin{array}{c}0.997^{* *} \\
(0.369)\end{array}$ \\
\hline$\sigma_{u}$ Constant & $\begin{array}{l}0.234^{* * *} \\
(0.025)\end{array}$ & $\begin{array}{l}0.232^{* * *} \\
(0.025)\end{array}$ & $\begin{array}{l}0.226^{* * *} \\
(0.025)\end{array}$ & $\begin{array}{l}0.228^{* * *} \\
(0.025)\end{array}$ & $\begin{array}{l}0.209 * * * \\
(0.025)\end{array}$ & $\begin{array}{l}0.240^{* * *} \\
(0.026)\end{array}$ & $\begin{array}{l}0.204^{* * *} \\
(0.024)\end{array}$ \\
\hline$\sigma_{e}$ Constant & $\begin{array}{l}0.189 * * * \\
(0.009)\end{array}$ & $\begin{array}{l}0.187^{* * *} \\
(0.009)\end{array}$ & $\begin{array}{l}0.186^{* * *} \\
(0.009)\end{array}$ & $\begin{array}{l}0.187^{* * *} \\
(0.009)\end{array}$ & $\begin{array}{l}0.189^{* * *} \\
(0.009)\end{array}$ & $\begin{array}{l}0.186^{* * *} \\
(0.009)\end{array}$ & $\begin{array}{l}0.180^{* * *} \\
(0.009)\end{array}$ \\
\hline Observations & 349 & 349 & 349 & 349 & 349 & 349 & 349 \\
\hline
\end{tabular}

Note. Standard errors are in parentheses.

${ }^{*} p<0.1 ;{ }^{* *} p<0.05 ;{ }^{* * *} p<0.01$.

a statistically significant impact on SPC. One plausible explanation for the apparently limited impact of conflicts of interest may be the relatively large numbers of suppliers available for patent legal services-our data show more than 1,400 U.S. patent law firms existing in the early 1990s. Thus, even if a few suppliers are conflicted, client firms may not be especially constrained in adjusting their supply portfolio concentration. Conflicts of interest are nonetheless a consideration in interpreting our findings and generalizing them to other settings.

One potential concern with our results is that a firm's reliance on outsourcing may be endogenous to our 
dependent variable. We evaluated these endogeneity concerns in two ways. First, we applied the techniques of Granger (1969) causality to evaluate whether lagged values of SPC contain useful information in predicting reliance on outsourcing, in addition to the lagged values of the latter variable. Using one-year lags, we find no empirical evidence that lagged SPC predicts (i.e., Granger causes) reliance on outsourcing. Second, we evaluate evidence for endogeneity by conducting a Hausman (1978) test for endogeneity, which compares estimates from our random-effects OLS model with twostage instrumental variables estimates for random-effects OLS. We use the average number of inventors per patent as an instrument for reliance on outsourcing. Again, we could not reject the null hypothesis that the estimated coefficients of the two models are statistically identical. Therefore, it appears unlikely that the firm's reliance on outsourcing is endogenous to its supply portfolio concentration. Nonetheless, we cannot rule out the possibility that "unobservables" may simultaneously influence both reliance on outsourcing and SPC. Choices regarding how much a firm relies on outsourcing may stem from various environmental (e.g., industry or market forces), historical (e.g., prior capability development), or exchange (e.g., expected firm specificity of projects) attributes, which may in turn influence supply portfolio concentration.

A further potential limitation of this study is that in developing a general theory of how domain diversity may affect a firm's supply choices, we have not considered how the capabilities of existing suppliers may condition this relationship. In particular, if the firm has an existing base of more specialized suppliers, it may experience a greater need to fragment its outsourcing among suppliers with higher domain diversity. In supplementary analyses, we examined this proposition with a variable, existing supply base, measured as the weighted average specialization of the firm's existing suppliers (using an HHI measure similar to domain diversity). The empirical results continue to show statistically significant support for the negative impact of domain diversity on SPC, but they also show that specialization of the firm's existing supply base exacerbates this effect. In other words, firms with a more specialized supply base make larger changes in their supply portfolio concentration (relative to firms with less specialized suppliers) in response to increasing or decreasing levels of domain diversity in their outsourced activities.

\section{Discussion and Conclusion}

This paper explains factors that impact concentration in a firm's supply portfolio, i.e., how outsourced knowledge-based service work, as a portfolio, is distributed among different suppliers. Our empirical analyses, which take advantage of rich data available in the context of outsourced patent prosecution work, show that firm-specific knowledge, interrelatedness of outsourced projects, reliance on outsourcing, domain diversity of outsourced work, and technological dynamism in the outsourcing domains are related to SPC in both statistical significance and economic impact. Subject to the empirical limitations noted above, the current study extends research on outsourcing in several important ways. First, we take a substantial step beyond a single transaction as the unit of analysis, which has been the mainstay of research on firm boundaries. Prior work has pointed to the presence of governance inseparability (Argyres and Liebeskind 1999) and knowledge and reputation spillovers between transactions (Mayer 2006), but their implications have largely been studied at the transaction level. Examining outsourcing at the portfolio level builds on this research stream but simultaneously sheds light on an aggregate phenomenon that is related to, but distinct from, transaction-level phenomena.

Specifically, the current paper draws attention to supplier management by firms at the portfolio level. Although prior research has addressed several aspects of supplier management, these analyses-consistent with the literature on outsourcing-have largely been at the level of individual outsourcing transactions or individual suppliers. Examining supplier concentration at the portfolio level explains how firms configure supply relationships at that level, which has valuable research and managerial implications (as suggested by the Cisco and Dell examples noted earlier in this paper) and is thus an important phenomenon that deserves further research attention. Additionally, we have described mechanisms at the portfolio level-in particular, relational governance and firm-specific knowledge embedded in a supplier relationship and the need for real-time coordination between transactions - that may lead firms to use more concentrated supplier portfolios. The imperative to adapt the firm's outsourcing portfolio either contemporaneously to diverse knowledge demands or dynamically to evolving ones acts as a countervailing force on these drivers of greater coordination with suppliers (and higher SPC). We highlight mechanisms that shed light on the simultaneous governance of a bundle or portfolio of transactions, and we draw on well-developed organizational economics theories that have previously examined these mechanisms as they apply to individual transactions.

In turn, by highlighting these portfolio-level considerations, we draw attention to their potential impact on transaction-level choices as well. For example, if a firm is more reliant on outsourcing at the portfolio level, it may employ a higher SPC and use more relational arrangements with suppliers, which imply a higher level of relational governance for each outsourced transaction than would be suggested by the transaction's 
attributes alone. Thus, governance decisions for individual transactions will likely be influenced by portfolio attributes, over and above transaction-level exchange characteristics. Prior studies have shown that the choice of supplier for a focal transaction is affected by other interrelated transactions, which are assumed to be exogenous for analytical convenience (Novak and Stern 2009, Parmigiani and Mitchell 2009); our research suggests that governance choices are likely to be made jointly for entire sets of transactions. Future work on outsourcing strategies at the transaction level can extend these insights by incorporating portfolio-level considerations in a more systematic manner. Additionally, in studying SPC, we have developed theoretically relevant variables at the portfolio level of analysis that are potentially valuable for future research on portfolio-level phenomena in outsourcing. Some of these variables-such as firm-specific knowledge and technological dynamism in our study-are simple portfolio-level averages of factors known to impact transaction-level outcomes. But others-such as interrelatedness, reliance on outsourcing, and domain diversity - are aggregations or compositions of transaction-level features that are uniquely relevant to portfolio-level analyses.

Concerning the extant literature on supplier management, our research contributes a number of novel insights on how firms configure their portfolio of suppliers in knowledge-based services. One finding is that the need for firm-specific knowledge in executing outsourced activities leads to greater supply concentration in the firm's outsourcing portfolio. Our research highlights the potential reusability of firm-specific knowledge investments and of relational governance that safeguards the exchange of sensitive knowledge across multiple outsourced transactions. Therefore, the average level of firm-specific knowledge across the firm's outsourcing portfolio impacts supplier and governance choices over and above the characteristics of individual transactions. This insight is valuable both for suppliers seeking to build closer relationships with client firms and for buyers seeking to manage their exposure to suppliers.

Recent literature on outsourcing has begun to explore the importance of interrelatedness between activities in the form of complementarities and scope economies that need to be actively leveraged along with firm boundary and supplier management choices. Thus far, research has primarily focused on the implications of such interdependencies on supplier choice (Hoetker 2006, Novak and Stern 2009) and concurrent sourcing (Parmigiani and Mitchell 2009). To these contributions, we add the insight that interrelatedness between outsourced activities also affects the composition of suppliers the firm uses at the portfolio level. A potentially valuable direction for future research is to examine interrelatedness across all firm projects-internalized and outsourcedthus deepening our understanding of concurrent sourcing in knowledge-based services.
A key finding of our study is that reliance on outsourcing increases the concentration of a firm's supply portfolio, an indication of increased strategic commitment to a smaller number of external suppliers. Outsourcing has been characterized with an element of strategic flexibility in the literature; rather than make commitments to internal capability development, firms outsource to tap into market forces and increase strategic flexibility (Quinn 2000). However, our research shows that a greater reliance on outsourcing may also render it more relational and thus takes away some of the flexibility and presumed choice that reliance on the market assumes. These empirical findings also add to prior research on the role of concurrent sourcing (or tapered integration), which primarily emphasizes capability (Rothaermel et al. 2006) and contract monitoring benefits (Parmigiani and Mitchell 2009) of simultaneously making and buying. Our empirical findings suggest an additional potential benefit, namely, firms that are less reliant on outsourcing-and employ concurrent sourcing-are able to use a less concentrated supply portfolio and thus draw more effectively on market forces for cost efficiency, flexibility, and access to capabilities.

Our empirical findings on domain diversity of the firm's outsourcing projects point to the enduring importance of supplier capabilities in firms' outsourcing decisions (Argyres 1996, Leiblein and Miller 2003). A firm seeking to consolidate its supply portfolio and reap the associated benefits must consider whether a more concentrated supply portfolio will provide it with the range of capabilities it needs. Our empirical results indicate that as the capability needs of a firm become more heterogeneous, it will likely need to diversify its supplier base. Therefore, even firms that appear to be relationally embedded with their current suppliers may take on new suppliers when they need to access different capabilities. In turn, diversification of capabilities may be a key supplier strategy for retaining clients and leveraging relational capital with them.

Additionally, we find that supply portfolios are likely to be less concentrated in technologically dynamic environments, where the risk of technological obsolescence and outdated supplier capabilities is high. Prior findings on the impact of technological dynamism (or uncertainty) on firm boundary decisions have been equivocal or mixed. Contrary to traditional predictions concerning technological uncertainty in transaction cost economics (Williamson 1985), Balakrishnan and Wernerfelt (1986) first modeled and found a pro-outsourcing effect of technological obsolescence. By contrast, other research studies have found no empirical evidence in either direction for tests of technological uncertainty on firm boundary decisions (Poppo and Zenger 1998, Walker and Weber 1984). After highlighting the potential bidirectional effects of technological dynamism, we draw on characteristics of outsourcing in knowledge-based services to 
suggest that the net impact may be in the direction of greater flexibility (and lower supply portfolio concentration) in this context. We find empirical support for this proposition. Thus, our theoretical logic and empirical findings regarding technological dynamism make some additional inroads into an enduring and important puzzle in the broader research literature on firm boundaries. More research is needed to delineate other conditions under which technological dynamism affects firm boundaries and outsourcing in this way.

Overall, this research indicates that freeing transaction cost theory from one of its foundational tenetsthat the transaction is the unit of analysis (Williamson 1985) - may have significant benefits for a vibrant organizational economics research program (Argyres and Liebeskind 1999), which will also provide additional strategic insights into how firms leverage internal and external capabilities for competitive advantage (Teece et al. 1997). This paper takes a first step by offering the firm's supply portfolio as the unit of analysis, and we anticipate that the next generation of research in this area will study and explain additional portfolio-level phenomena, apart from supply concentration. In conclusion, this paper provides early evidence that managers and scholars focusing on organizational boundary choices would do well to take into account the ecosystem of relationships between firms and their suppliers beyond the transactional level. These higher-level strategic considerations will likely lead to a richer explanation of organizational boundaries, dynamic capability development, interorganizational coordination, and supplier management.

\section{Electronic Companion}

An electronic companion to this paper is available as part of the online version at http://dx.doi.org/10.1287/orsc.1110.0725.

\section{Acknowledgments}

The authors gratefully acknowledge valuable comments from Rajshree Agarwal, Jovan Grahovac, Martine Haas, Rahul Kapoor, Nandini Lahiri, Anne Parmigiani, Ali Tafti, Brian Wu, two anonymous referees, and senior editor Nicholas Argyres. They also received valuable feedback from presentations at the Atlanta Competitive Advantage Conference (Georgia State University 2010), Midwest Strategy Meetings (Kellogg School of Management 2010), University of Illinois (2010), MidAtlantic Strategy Colloquium (University of Maryland 2010), and the ASQ-HEC-OMT conference on "Coordination Within and Among Organizations" (HEC Paris 2011).

\section{Endnotes}

${ }^{1}$ In some areas, Cisco concentrated its outsourcing even more sharply: from 13 to 4 suppliers in electronics manufacturing services and from 20 suppliers to just 3 in application-specific integrated circuits. Cisco's changes in supply portfolio concentration were wide-ranging and spanned multiple areas, but we focus on narrower domains, where all the outsourcing is for the "same type" of knowledge-based work (e.g., applicationspecific integrated circuit design).
${ }^{2}$ See Bureau of Economic Analysis. Gross-domestic-product(GDP)-by-industry data. Accessed June 4, 2010, http://www .bea.gov/industry/gdpbyind_data.htm.

${ }^{3}$ Manufacturing often entails significant scale economies and large fixed-cost investments in equipment or engineering, which can be key drivers of outsourcing decisions. Furthermore, suppliers or buyers may sometimes enjoy significant market power in manufacturing, such that there is little autonomy to choose among exchange partners. In knowledge-based services, however, scale advantages, fixed-cost investments, and market power are all quite limited; thus each new activity or project can typically be outsourced to one of several different suppliers.

${ }^{4}$ In the patent context, for example, evaluating patent (legal) quality is quite costly and imperfect, especially in the unclear and abstract stage when a patent is newly issued. Firms typically only use independent patent attorneys to evaluate patents when litigation is a looming possibility (i.e., quite rarely) and at considerable expense.

${ }^{5}$ The intuition behind adjusting the HHI in this way derives simply from the fact that an $\mathrm{HHI}$ is a Euclidean distance based on fraction (or share) vectors that reside along $N$ orthogonal axes. Relatedness implies that the axes are, in fact, not orthogonal, and correlation is a natural way to measure the "angle" between them.

${ }^{6}$ One concern from an empirical perspective is that conflicts of interest may not give firms latitude in choosing suppliers for legal services. However, we found that law firms routinely perform patent prosecution services for multiple clients, even within a relatively narrow technological domain (we found this to be the case at the 4-, 7-, and 10-digit IPC levels). However, conflicts of interest may add some noise - on the margin - to our dependent variable, which militates against finding support for our hypotheses. We thus perform a somewhat conservative test.

\section{References}

Afuah, A. 2001. Dynamic boundaries of the firm: Are firms better off being vertically integrated in the face of technological change? Acad. Management J. 44(6) 1211-1228.

Akerlof, G. A. 1970. The market for lemons: Quality uncertainty and market mechanism. Quart. J. Econom. 84(3) 488-500.

Alchian, A. A., H. Demsetz. 1972. Production, information costs, and economic organization. Amer. Econom. Rev. 62(5) 777-795.

Anderson, E., D. Schmittlein. 1984. Integration of the sales forces: An empirical examination. RAND J. Econom. 15(3) 385-395.

Argyres, N. 1996. Evidence on the role of firm capabilities in vertical integration decisions. Strategic Management J. 17(2) 129-150.

Argyres, N. S., J. P. Liebeskind. 1999. Contractual commitments, bargaining power, and governance inseparability: Incorporating history into transaction cost theory. Acad. Management Rev. 24(1) 49-63.

Argyres, N., T. Zenger. 2012. Capabilities, transaction costs, and firm boundaries. Organ. Sci. 23(6) 1643-1657.

Arrow, K. J. 1974. The Limits of Organization. W. W. Norton \& Company, New York.

Bakos, J. Y., E. Brynjolfsson. 1993. Information technology, incentives, and the optimal number of suppliers. J. Management Inform. Systems 10(2) 37-53.

Balakrishnan, S., B. Wernerfelt. 1986. Technical change, competition and vertical integration. Strategic Management J. 7(5) 347-359. 
Barzel, Y. 1982. Measurement cost and the organization of markets. J. Law Econom. 25(1) 27-48.

Borgatti, S. P., M. G. Everett, L. C. Freeman. 2002. UCINET for Windows: Software for social science network analysis. Analytic Technologies, Harvard, MA.

Carbone, J. 2006. Supply chain manager of the year: Steve Darendinger, champion of change. Purchasing (September 21) 42.

Clemons, E. K., S. P. Reddi, M. C. Row. 1993. The impact of information technology on the organization of economic activity: The "move to the middle" hypothesis. J. Management Inform. Systems 10(2) 9-35.

Coff, R. W. 1999. When competitive advantage doesn't lead to performance: The resource-base view and stakeholder bargaining power. Organ. Sci. 10(2) 119-133.

Dierickx, I., K. Cool. 1989. Asset stock accumulation and sustainability of competitive advantage. Management Sci. 35(12) 1504-1511.

Dyer, J. H., H. Singh. 1998. The relational view: Cooperative strategy and sources of interorganizational competitive advantage. Acad. Management Rev. 23(4) 660-679.

Ghemawat, P., P. del Sol. 1998. Commitment versus flexibility? Calif. Management Rev. 40(4) 26-41.

Granger, C. W. J. 1969. Investigating causal relations by econometric models and cross-spectral methods. Econometrica 37(3) $424-438$

Greene, W. 2004. Fixed effects and bias due to the incidental parameters problem in the Tobit model. Econometric Rev. 23(2) $125-147$.

Hall, B. 2002. A note on the bias in the Herfindahl-type measures based on count data. A. B. Jaffe, M. Trajtenberg, eds. Patents, Citations, and Innovations: A Window on the Knowledge Economy. MIT Press, Cambridge, MA, 454-459.

Hall, B. H., A. B. Jaffe, M. Trajtenberg. 2001. The NBER patent citations data file: Lessons, insights, and methodological tools. NBER Working Paper 8498, National Bureau of Economic Research, Cambridge, MA.

Harrigan, K. R. 1986. Matching vertical integration strategies to competitive conditions. Strategic Management J. 7(6) 535-555.

Hatch, N. W., D. C. Mowery. 1998. Process innovation and learning by doing in semiconductor manufacturing. Management Sci. 44(11) 1461-1477.

Hausman, J. A. 1978. Specification tests in econometrics. Econometrica 46(6) 1251-1271.

Helfat, C. 1994. Firm-specificity in corporate applied R\&D. Organ. Sci. 5(2) 173-184.

Hoetker, G. 2005. How much you know versus how well I know you: Selecting a supplier for a technically innovative component. Strategic Management J. 26(1) 75-96.

Hoetker, G. 2006. Do modular products lead to modular organizations? Strategic Management J. 27(6) 501-518.

Hoetker, G., T. Mellewigt. 2009. Choice and performance of governance mechanisms: Matching alliance governance to asset type. Strategic Management J. 30(10) 1025-1044.

Jaffe, A. B. 1998. The importance of "spillovers" in the policy mission of the advanced technology program. J. Tech. Transfer 23(2) $11-19$.

Jaffe, A. B., M. S. Fogarty, B. A. Banks. 1998. Evidence from patents and patent citations on the impact of NASA and other federal labs on commercial innovation. J. Indust. Econom. 46(2) 183-205.
Jones, G. R. 1984. Task visibility, free riding and shirking: Explaining the effect of structure and technology on employee behavior. Acad. Management Rev. 9(4) 684-695.

Kang, M. P., J. T. Mahoney, D. C. Tan. 2009. Why firms make unilateral investments specific to other firms: The case of OEM suppliers. Strategic Management J. 30(2) 117-135.

Kim, S. M., J. T. Mahoney. 2006. Mutual commitment to support exchange: Relation-specific IT system as a substitute for managerial hierarchy. Strategic Management J. 27(5) 401-423.

Klein, B., K. B. Leffler. 1981. The role of market forces in assuring contractual performance. J. Political Econom. 89(4) 615-641.

Lajili, K., J. T. Mahoney. 2006. Revisiting agency and transaction costs theory predictions on vertical financial ownership and contracting: Electronic integration as an organizational form choice. Managerial Decision Econom. 27(7) 573-586.

Lajili, K., M. Madunic, J. T. Mahoney. 2007. Testing organizational economics theories of vertical integration. Res. Methodol. Strategy Management 4(1) 343-369.

Leiblein, M. J., D. J. Miller. 2003. An empirical examination of transaction- and firm-level influences on the vertical boundaries of the firm. Strategic Management J. 24(9) 839-859.

Lerner, J. 1995. Patenting in the shadow of competitors. J. Law Econom. 38(2) 463-495.

Macneil, I. R. 1980. The New Social Contract. Yale University Press, New Haven, CT.

Madsen, T. L., E. Mosakowski, S. Zaheer. 2003. Knowledge retention and personnel mobility: The non-disruptive effects of inflows of experience. Organ. Sci. 14(2) 173-191.

Mahoney, J. T. 1992. The choice of organizational form-Vertical financial ownership versus other methods of vertical integration. Strategic Management J. 13(8) 559-584.

Matyas, L., P. Sevestre, eds. 2008. The Econometrics of Panel Data. Springer, Dordrecht, The Netherlands.

Mayer, K. J. 2006. Spillovers and governance: An analysis of knowledge and reputational spillovers in information technology. Acad. Management J. 49(1) 69-84.

Mayer, K. J., N. S. Argyres. 2004. Learning to contract: Evidence from the personal computer industry. Organ. Sci. 15(4) 394-410.

Mayer, K. J., R. M. Salomon. 2006. Capabilities, contractual hazards, and governance: Integrating resource-based and transaction cost perspectives. Acad. Management J. 49(5) 942-959.

Mayer, K. J., D. Somaya, I. O. Williamson. 2012. Firm-specific, industry-specific, and occupational human capital and the sourcing of knowledge work. Organ. Sci. 23(5) 1311-1329.

Milgrom, P., J. Roberts. 1995. Complementarities and fit: Strategy, structure, and organizational change in manufacturing. J. Accounting Econom. 19(2) 179-208.

Nelson, R. R. 1991. Why do firms differ, and how does it matter? Strategic Management J. 12(S2) 61-74.

Nelson, R. R., S. G. Winter. 1982. An Evolutionary Theory of Economic Change. Harvard University Press, Cambridge, MA

Nickerson, J. A., T. R. Zenger 2004. A knowledge-based theory of the firm-The problem-solving perspective. Organ. Sci. 15(6) 617-632.

Novak, S., S. Stern. 2009. Complementarity among vertical integration decisions: Evidence from automobile product development. Management Sci. 55(2) 311-332.

Oddi, A. S. 2004. Patent attorney malpractice: An oxymoron no more. J. Law, Tech. Policy 1 1-72. 
Ouchi, W. G. 1979. Conceptual-framework for the design of organizational control mechanisms. Management Sci. 25(9) 833-848.

Parmigiani, A. 2007. Why do firms both make and buy? An investigation of concurrent sourcing. Strategic Management J. 28(3) 285-311.

Parmigiani, A., W. Mitchell. 2009. Complementarity, capabilities, and the boundaries of the firm: The impact of within-firm and interfirm expertise on concurrent sourcing of complementary components. Strategic Management J. 30(10) 1065-1091.

Poppo, L., T. R. Zenger. 1998. Testing alternative theories of the firm: Transaction cost, knowledge-based, and measurement explanations for make-or-buy decisions in information services. Strategic Management J. 19(9) 853-877.

Poppo, L., T. R. Zenger. 2002. Do formal contracts and relational governance function as substitutes or complements? Strategic Management J. 23(8) 707-725.

Quinn, J. B. 2000. Outsourcing innovation: The new engine of growth. Sloan Management Rev. 41(4) 13-28.

Rangan, V. K., M. Bell. 1999. Dell online. HBS Case 9-598-116, Harvard Business School, Boston.

Rothaermel, F. T., M. A. Hitt, L. A. Jobe. 2006. Balancing vertical integration and strategic outsourcing: Effects on product portfolio, product success, and firm performance. Strategic Management J. 27(11) 1033-1056.

Sanchez, R., J. T. Mahoney. 1996. Modularity, flexibility, and knowledge management in product and organization design. Strategic Management J. 17(Winter special issue) 63-76.

Shao, M., H. Lee. 2009. Cisco Systems, Inc.: Collaborating on new product introduction. Stanford Graduate School of Business Case GS-66, Stanford University, Stanford, CA.

Siggelkow, N. 2002. Misperceiving interactions among complements and substitutes: Organizational consequences. Management Sci. 48(7) 900-916.

Somaya, D. 2003. Strategic determinants of decisions not to settle patent litigation. Strategic Management J. 24(1)17-38.

Srinivasan, R., T. H. Brush. 2006. Supplier performance in vertical alliances: The effects of self-enforcing agreements and enforceable contracts. Organ. Sci. 17(4) 436-452.

Teece, D. J. 1980. Economies of scope and the scope of the enterprise. J. Econom. Behav. Organ. 1(3) 223-247.

Teece, D. J., G. Pisano, A. Shuen. 1997. Dynamic capabilities and strategic management. Strategic Management J. 18(7) 509-533.

Telser, L. G. 1980. Theory of self-enforcing agreements. J. Bus. 53(1) $27-44$.
Tobin, J. 1958. Estimation of relationships for limited dependentvariables. Econometrica 26(1) 24-36.

von Nordenflycht, A. 2010. What is a professional service firm? Toward a theory and taxonomy of knowledge-intensive firms. Acad. Management Rev. 35(1) 155-174.

Walker, G., D. Weber. 1984. A transaction cost approach to make-orbuy decisions. Admin. Sci. Quart. 29(3) 373-391.

Wang, H., W. R. Chen. 2010. Firm-specificity in technological innovation and rent appropriation: The roles of environmental dynamism and technological diversity. Res. Policy 39(1) 141-154.

Wang, H., J. He, J. T. Mahoney. 2009. Firm-specific knowledge resources and competitive advantage: The roles of economic- and relationship-based employee governance mechanisms. Strategic Management J. 30(12) 1265-1285.

Williamson, O. E. 1985. The Economic Institutions of Capitalism. Free Press, New York.

Williamson, O. E. 1999. Strategy research: Governance and competence perspectives. Strategic Management J. 20(12) 1087-1108.

Ziliak, S. T., D. N. McCloskey. 2004. Size matters: The standard error of regressions in the American Economic Review. J. SocioEconom. 33(5) 331-344.

Mahka Moeen is a doctoral candidate of strategy and entrepreneurship at the Robert H. Smith School of Business, University of Maryland. Her research focuses on firm's reconfiguration strategies and the implications for strategic renewal and industry evolution.

Deepak Somaya is the Steven and Christy King Faculty Fellow and associate professor of strategy and entrepreneurship at the College of Business, University of Illinois at Urbana-Champaign. He received his Ph.D. from the Walter A. Haas School of Business, University of California, Berkeley. His research seeks to understand how companies strategize about and derive competitive advantage from knowledge assets that are embedded in knowledge workers and intellectual property.

Joseph T. Mahoney is the Caterpillar Chair of Business and a professor of strategy and entrepreneurship at the College of Business, University of Illinois at Urbana-Champaign. He received his Ph.D. from the Wharton School of Business, University of Pennsylvania. His research focuses on the economic foundations of strategy.

\section{CORRECTION}

In this article, "Supply Portfolio Concentration in Outsourced Knowledge-Based Services" by Mahka Moeen, Deepak Somaya, and Joseph T. Mahoney (first published in Articles in Advance April 3, 2012, Organization Science, http://dx.doi.org/10.1287/orsc.1110.0725), the following references have been added to the reference list and cited in text:

Bakos, J. Y., E. Brynjolfsson. 1993. Information technology, incentives, and the optimal number of suppliers. J. Management Inform. Systems 10(2) 37-53.

Clemons, E. K., S. P. Reddi, M. C. Row. 1993. The impact of information technology on the organization of economic activity: The "move to the middle" hypothesis. J. Management Inform. Systems 10(2) 9-35. 